\title{
A parametric study of volume and surface judgments'
}

\section{RICHARD J. STANEK ${ }^{2}$ UNIVERSITY OF SANTA CLARA ${ }^{3}$}

Ten prisms and 10 plates differing in height were presented to 30 male and 30 female college students whose task was to judge volume and surface of the solids. No sex differences in volume or surface estimates were found. Increasing the height of a prism from a cube initially resulted in underestimates of volume; for prisms whose heights deviated markedly from a cube, a consistent and steadily increasing tendency to overestimate volume occurred. Decreasing the height of a plate from a cube initially had no significant effect on surface estimates, but with a marked decrease in height, a consistent and steadily increasing tendency to underestimate surface resulted.

While a modest research literature regarding the influence of different two-dimensional shapes on judgments of area has accumulated (Anastasi, 1936; Estes, 1961; Smith, 1964; Warren \& Pinneau, 1955), very little effort has been devoted to exploring the effect of three-dimensional shapes on judgments of surface and/or volume. A few experiments reported in Brunswik (1956) and a recent study by Stanek (1968) appear to reflect the extent of published research having to do with surface or volume judgments of solids. Since certain results of research involving two-dimensional shapes are relevant to the present research a few of these studies will be briefly reviewed.

Anastasi (1936) described a study by Peters in which children were asked to judge areas of 12 different shapes. A long linear dimension in a shape was found to increase the apparent size of the figure.

Estes (1961) in addition to studying the relationship of shape to size judgments explored the influence of sex and age on judgments of area of two-dimensional forms. For her male and female groups, which consisted of kindergarteners, grammar school children, and college students, no sex differences in judging areas of two-dimensional figures were established.

Warren and Pinneau (1955) asked subjects (Ss) to judge the areas of circles, squares, crosses, and triangles. They found that despite instructions to equate forms on the basis of total area of figure, Ss tended to employ the maximum vertical dimension in equating forms.

A study reported in Brunswik (1956) involving 12 Ss who máde volume and surface judgments of variously shaped solids revealed relatively accurate volume and surface judgments of elongated priams but a tendency toward underestimation of surfaces of flat objects.

Finally, in a study reported in this joumal, Stanek (1968) explored the influence of various shapes of three-dimensional solids on estimates of both surface and volume in a group of 20 college students. The shape that exerted the most pronounced effect was found to be a thin square plate $(7.39 \times 7.39 \times .30 \mathrm{~cm})$, resulting in a marked underestimation of surface, and a long square prism $(.75 \times .75 \times 29.13 \mathrm{~cm})$ resulting in an overestimation of volume. The remaining eight solids having various shapes, e.g., sphere, pyramid, cone, etc., were found to have no consistent or marked effect on volume or surface judgments.

The present study was designed to pursue further the role of height of solid in estimates of surface and volume. Two series of objects with 10 heights in each series were employed. The increments or decrements in height were all equal, thus making possible trend analysis of the data. The hypotheses for the study were: (1) As the height of a prism is regularly increased its volume will be overestimated in a steadily increasing manner. (2) As the height of a plate is steadily decreased its surface will be underestimated in a steadily increasing manner. Thus, a linear relationship is postulated between height of solid and volume judgments and height of solid and surface judgments. (3) The sex of $S$ will have no differential effect on judged volume or surface of prisms or plates, respectively.

\section{Subjects}

\section{METHOD}

Thirty male (M) and 30 female (F) undergraduate students at the University of Santa Clara participated in the study.

\section{Apparatus}

The standard stimuli employed in the judgment of volume consisted of 10 prisms whose bases were $2 \mathrm{~cm}^{2}$ and whose heights increased from $2 \mathrm{~cm}$ (a cube) to $29 \mathrm{~cm}$ in $3 \mathrm{~cm}$ increments (see Table 1 for actual heights and volumes of prisms). The standard stimuli employed in the judgment of surface consisted of 10 plates whose bases where $5 \mathrm{~cm}^{2}$ and whose heights decreased from $5 \mathrm{~cm}$ (a cube) to $.5 \mathrm{~cm}$ (see Table 2 for actual heights and surfaces of plates). Volume and surface values represented the point of objective equality (POE) for the 10 prisms and plates, respectively.

The comparison series consisted of 12 cubes whose sides ranged from $1.04 \mathrm{~cm}$ to $6.54 \mathrm{~cm}$ in increments of $.5 \mathrm{~cm}$. The resulting volumes for the comparison series in $\mathrm{cm}^{3}$ were (rounded to integral values): $1,4,8,16,28,44,66,94,128,170,220$, and 280. The resulting surfaces for the same series in $\mathrm{cm}^{2}$ were (rounded to integral values): $6,14,25,39,55,75,98,124,152$, 184,219 , and 257 . The volume and surface values of the comparison series of cubes were used as the basis for the point of subjective equality (PSE), since Ss were asked to equate the standard stimuli to one of these comparison series for all volume and surface estimates.

The total volumes and surfaces for the standard and comparison series were recorded on the faces of the solids pointing away from S's view but in direct view of the $E$ to facilitate recording of PSEs. All stimuli were painted a dull, neutral gray ( $43 \%$ reflectance).

The comparison series was situated from S's left to right, from smallest to largest, at a $1-\mathrm{m}$ distance from $S$ on a table covered with black velour cloth. Each standard stimulus was presented singly at a $.5-\mathrm{m}$ distance from $S$ and in the center of the comparison series.

\section{Procedure}

The 30 male and 30 female Ss were randomly assigned to 1 of 10 sequences in a replicated Latin square design for volume and surface conditions. Thus, 10 groups of three $S s$ each were given different sequences of the 10 prisms for volume judgments and 10 plates for surface judgments.

Each $S$ was presented with each of the 10 standard stimuli with 
Table 1

POE, PSE, and CE Values for Vohume Judgments of 10 Heigh ts of Prisms for Males and Females

\begin{tabular}{lrrrrrrrrr}
\hline \multicolumn{2}{l}{ Height of Height:Base POE } & \multicolumn{3}{c}{ PSE $\left(\mathrm{cm}^{3}\right)$} & \multicolumn{3}{c}{ CE $\left(\mathrm{cm}^{3}\right)$} \\
Prism (cm) & Ratio & $\begin{array}{l}\text { Volumes of } \\
\text { Prisms }\left(\mathrm{cm}^{3}\right)\end{array}$ & M & F & Both & M & F & Both \\
\hline 2 (cube) & $1: 1$ & 8 & & 7.6 & 7.7 & 7.7 & -0.4 & -0.3 & -0.3 \\
5 & $2.5: 1$ & 20 & 15.9 & 20.4 & 18.1 & -4.1 & 0.4 & -1.9 \\
8 & $4: 1$ & 32 & 29.2 & 28.1 & 28.7 & -2.8 & -3.9 & -3.3 \\
11 & $5.5: 1$ & 44 & 41.3 & 38.0 & 39.6 & -2.7 & -6.0 & -4.4 \\
14 & $7: 1$ & 56 & 51.8 & 49.7 & 50.7 & -5.2 & -6.3 & -5.7 \\
17 & $8.5: 1$ & 68 & 70.6 & 66.9 & 68.8 & 2.6 & -1.1 & 0.8 \\
20 & $10: 1$ & 80 & 92.8 & 82.9 & 87.9 & 12.8 & 2.9 & 7.9 \\
23 & $11.5: 1$ & 92 & 113.3 & 102.6 & 108.0 & 21.3 & 10.6 & 16.0 \\
26 & $13: 1$ & 104 & 130.2 & 120.8 & 125.6 & 26.2 & 16.8 & 21.6 \\
29 & $14.5: 1$ & 116 & 157.1 & 136.3 & 146.7 & 41.1 & 20.3 & 30.7 \\
\hline
\end{tabular}

height in a vertical orientation singly for a $5-\sec$ exposure, after which time $S$ was asked to identify the one solid in the comparison series that matched the standard prism or plate for either its volume or surface. Volume and surface judgments were presented in a counterbalanced order, although all judgments of one kind, say volume, were completed before judgments of the other kind were made. All Ss were given specific instructions with examples regarding the meaning of the magnitudes judged, volume and surface. All judgments were based on visual inspection of the stimuli only.

Observations employed in the data analysis consisted of constant errors (CE) that were determined by subtracting POE from PSE. A negative CE thus indicated an underestimate and a positive $\mathrm{CE}$ an overestimate of volume and/or surface.

\section{RESULTS AND DISCUSSION}

The results of a replicated Latin square analysis of variance revealed a significant effect of height of solid on judged volume $(F=15.661, \mathrm{df}=9 / 360, \mathrm{p}<.001)$ as well as on judged surface $(F=5.808$, df $=9 / 360, p<.001)$. However, sex had no differential effect on $S$ 's judgments of either volume or surface $(F=1.230, \mathrm{df}=1 / 40$, and $F=0.786$, df $=1 / 40$, respectively), a finding similar to the result established in the Estes research (1961) in which no sex differences were established for area judgments of two-dimensional forms across many age levels.
Table 2

POE, PSE, and CE for Surface Judgments of 10 Heights of Plates for Males and Females

\begin{tabular}{|c|c|c|c|c|c|c|c|c|}
\hline \multicolumn{2}{|c|}{ Height of Height:Base } & POE & \multicolumn{3}{|c|}{$\operatorname{PSE}\left(\mathrm{cm}^{2}\right)$} & \multicolumn{3}{|c|}{$\mathrm{CE}\left(\mathrm{cm}^{2}\right)$} \\
\hline Plate (cm) & Ratio & $\begin{array}{l}\text { Surface of } \\
\text { Plates }\left(\mathrm{cm}^{2}\right)\end{array}$ & $\mathbf{M}$ & $\mathbf{F}$ & Both & $\mathbf{M}$ & $\mathbf{F}$ & Both \\
\hline .5 & $.1: 1$ & 60 & 43.7 & 49.7 & 46.7 & -16.3 & -11.3 & $3-13.3$ \\
\hline 1.0 & $.2: 1$ & 70 & 59.9 & 56.8 & 58.4 & -10.1 & -13.2 & $2-11.6$ \\
\hline 1.5 & $.3: 1$ & 80 & 71.3 & 67.2 & 69.3 & -8.7 & -12.8 & -10.7 \\
\hline 2.0 & $.4: 1$ & 90 & 86.9 & 85.0 & 86.0 & -3.1 & -5.0 & $9-4.0$ \\
\hline 2.5 & $.5: 1$ & 100 & 95.4 & 93.1 & 94.3 & -4.6 & -6.9 & -5.7 \\
\hline 3.0 & $.6: 1$ & 110 & 111.5 & 109.0 & 110.3 & 1.5 & -1.0 & 0.3 \\
\hline 3.5 & $.7: 1$ & 120 & 119.9 & 117.5 & 118.8 & -0.1 & -2.5 & $5-1.2$ \\
\hline 4.0 & $.8: 1$ & 130 & 131.7 & 124.4 & 128.1 & 1.7 & -5.6 & -1.9 \\
\hline 4.5 & $.9: 1$ & 140 & 138.9 & 132.6 & 135.8 & -1.1 & -7.4 & -4.2 \\
\hline 5.0 (cube) & $1: 1$ & 150 & 150.4 & 147.6 & 149.0 & 0.4 & -3.4 & -1.0 \\
\hline
\end{tabular}

The direction of the effect of height of solid on judgments can be discerned by considering the $\mathrm{CE}$ values tabulated in Tables 1 and 2 and presented graphically in Fig. 1. In regard to volume, as heights of prisms increased an initial underestimation occurred, followed by increasing degrees of overestimation, a finding that corroborates a result of the earlier study by Stanek (1968) where volume of an elongated prism was overestimated. In addition, the study by Anastasi (1936) suggested that long linear dimensions tend to increase apparent sizes of two-dimensional figures. This same linear cue appears to be involved in judging solids since volumes of elongated prisms were overestimated in this study. The marked influence of height of prisms on judgments of volume also seems to be consistent with the finding in the Warren and Pinneau study (1955) in which a strong tendency to use maximum vertical dimensions in judging areas of two-dimensional forms was identified.

In regard to surface, reading up from the bottom of Table 2, as height of plate is decreased an initial and slight underestimation of surface eventually develops into a consistent and steadily increasing tendency toward underestimation, substantiating a finding from the previous study by Stanek (1968) in which surface of a plate was found to be markedly underestimated. The study reported in Brunswik (1956) also revealed that surfaces of objects spread out in space were consistently underestimated.

Since significant $F$ values were found for both volume and

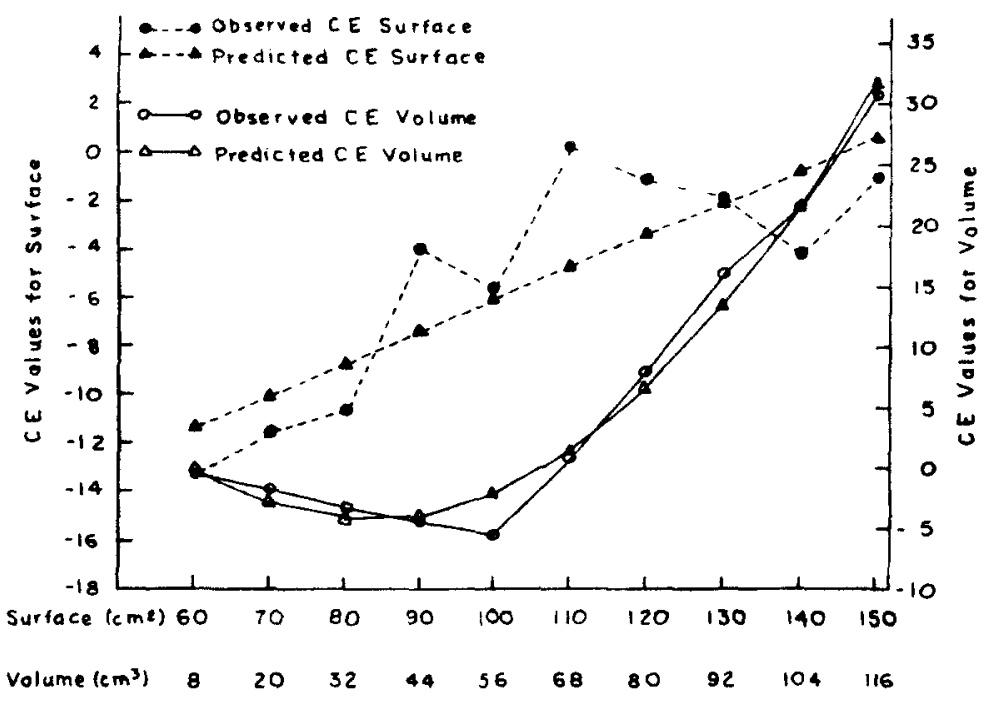

Dimension of Plate or Prism

Fig. 1. CE values for judgments of volume and surface. 
surface judgments, trend analyses were applied to the data. The results of the trend analysis for volume revealed no significant components of variance beyond a quadratic trend $[F(\operatorname{lin})=102.851, \quad$ df $=1 / 360, p<.001 ; \quad F($ nonlin $)=4.763$, df $=8 / 360, p<.001 ; F(q u a d)=35.728$, df $=1 / 360, p<.001 ;$ $F($ cub $)=0.228, \mathrm{df}=1 / 360$ ]. Thus, two trends were apparent in the relationship between height of prism and judged volume: (1) a decrease in judged volume for prisms slightly taller than a cube and (2) a consistent overestimation of volume as height of prism departs more and more from a cube. The first hypothesis of this study then is corroborated for heights beyond a certain magnitude, i.e., those prisms having height:base ratios of 10:1 or greater.

The trend analysis between height of plate and judged surface revealed only a linear trend $[\mathrm{F}(\mathrm{lin})=36.134$, df $=1 / 360$, $p<.001 ; \quad F($ nonlin $)=2.017$, df $=8 / 360]$. However, judged surface is not consistently underestimated until the plate with a height:base ratio of $.5: 1$ is reached. Thereafter, judged surface is underestimated to a greater and greater degree as height of plate is decreased, as was predicted in the second hypothesis.

The regression line for volume has been plotted in Fig. 1 and the second degree polynomial equation for predicting volume estimates from heights of prisms was found to be $\dot{X}=6.1+$ $1.745 \mathrm{a}+1.626 \mathrm{~b}$, where 6.1 was the overall mean $\mathrm{CE}$ for volume judgments and $a$ and $b$ were the orthogonal coefficients for each height of prism. A test for goodness of fit revealed that this second degree equation provided an adequate fit for the observed data $(F=0.339$, $d f=1 / 360)$.

As a measure of the degree of association between height of prism and judged volume, a correlation ratio was calculated, yielding a value of .49. Consequently, roughly $24 \%$ of the variance in volume judgments may be accounted for by height of prism.

The regression line for surface has also been plotted in Fig. 1. The first degree equation for predicting surface judgments from heights of plates was found to be: $X=-5.4+.669 a$, in which -5.4 was the overall mean $C E$ for surface judgments and a was the orthogonal coefficient for each height of plate. A test for departure from pattern revealed that the first degree equation was an adequate fit for the observed means $(F=2.018, \mathrm{df}=1 / 360)$. The linear correlation between judged surface and height of plate was found to be .25 , so that approximately $6 \%$ of the variance in surface judgments may be attributed to height of plate. Thus, the degree of association between height of solid and judgment is much stronger for volume than for surface estimates.

Finally, if one disregards the absolute dimensions of the prisms and the plates and considers both sets of solids to exist along the same dimension of height, the series ranges from a solid with a minimal height (height:base ratio of $.1: 1$ ), through a cube (1:1), to a very elongated solid $(14.5: 1)$. Further research, involving both surface and volume judgments for a series of solids, incorporating both sets of heights employed in this study, should clarify the nature of the relationship between the whole range of heights of solids and their judged surface and volume.

In conclusion: (1) sex provides no particular advantage in estimates of volume or surface of prisms or plates of varying heights; (2) the relationship between height of prism and judged volume is not a simple linear one; as height of prism increases an initial decrease in judged volume occurs but with increasing height volume is consistently and increasingly overestimated; (3) the relationship between height of plate and judged surface is a linear one, i.e., as height of plate is steadily decreased, surface is underestimated and becomes a consistent pattern when height:base ratio decreases to $.5: 1$; (4) the degree of relationship between height of prism and judged volume is much stronger than between height of plate and judged surface; (5) the height:base ratio may be related to judged volume and/or surface but knowledge of the exact role such a factor plays in judgments must await further research. The influence of spatial orientation of solids, i.e., vertical or horizontal, would be an additional variable to investigate.

\section{REFERENCES}

ANASTASI, A. The estimation of area. Joumal of General Psychology, $1936,14,201-225$.

BRUNSWIK, E. Perception and the representative design of psycholozical experiments Berkeley, California: University of Califomia Press, 1956.

ESTES, B. W. Judgment of size in relation to geometric shape. Child Development. 1961, 32, 277-286.

KIRK, R. E. Experimental dexign: Procedures for the behavioral sciences. Belmont, Califomia: Wadsworth, 1968.

SMITH, J. P. The effects of figural shape in the perception of area. (Doctoral dissertation, Fordham University) Ann Arbor, Mich., University Microfims, 1964, No. 64-13, 230.

STANEK, R. J. Surface and volume judgments of three-dimensional shapes. Psychonomic Science, 1968, 11, 121-122.

WARREN, J. M., PINNEAU, S. R. Influence of form on judgment of apparent area. Perceptual \& Motor Skills, 1955, 5, 7-10.

\section{NOTES}

1. This research was initiated while the author was working under an NSF Academic Year Extension Grant aw arded in 1965 and terminated in 1967.

2. The author wishes to express his appreciation to D. Swangren who assisted in the data collection phase of the study.

3. Address: Department of Psychology, University of Santa Clara, Santa Clara, California 95053.

(Accepted for publication December 4, 1968.) 